\title{
AGENESIS OF THIRD MOLARS IN ORTHODONTIC PATIENTS ATTENDING DHULIKHEL HOSPITAL
}

\author{
Dr. Chandan Upadhyaya, ${ }^{1}$ Dr. Bhoj Raj Adhikari, ${ }^{2}$ Dr. Dashrath Kafle, ${ }^{3}$ Dr. Manoj Humagain ${ }^{4}$ \\ 1. Assitant Professor, 2. Dental Surgeon, 3. Lecturer, 4. Assistant Professor
}

Kathmandu University School of Medical Sciences, Dhulikhel

Correspondence : updch@yahoo.com

Aims and objective: The aim of this descriptive study was to determine the prevalence of agenesis or congenitally missing third molars in orthodontic patients attending Dhulikhel Hospital.

Materials and method: A retrospective study of a total of 294 patients, of both genders ranging from 12 to 34 years of age who were orthodontically treated between August, 2010 to May 2012, were reviewed from the files of the Department of Orthodontics, Dhulikhel Hospital, Kathmandu University Hospital. The records included panoramic radiographs and study models of all patients with intra oral photographs at the beginning of treatment.

Results: It shows that agenesis of one to four third molars was present in male group in 63 cases out of 94 , i.e, $67.02 \%$ and in the female group in 85 cases out of 200 , i.e. in $42.5 \%$. In the group of male and female together, we found the agenesis of one to four third molars in 148 cases, which is $50.34 \%$.

Conclusion: Data concerning the incidence of third molars agenesis belong to the essential characteristics of the dentition's status of the given population. Dental developmental anomalies can indicate the degree of genetic load of individuals and relatives. By analyzing the global term "agenesis of one to four third molars" it is possible to receive data, which are quite significant for the orthodontic treatment plan.

Key Words: agenesis, panoramic radiographs, prevalence, third molars

\section{INTRODUCTION:}

Tooth agenesis, which is defined as the congenital absence of one or more primary or permanent teeth, is one of the most frequent human dental anomalies (Symonset al., 1993; Cameron and Sampson, 1996; Vastardis, 2000) ${ }^{1}$. The process of development and eruption of third molar has been shown to be highly variable. The third molar is the most common congenitally missing tooth and its prevalence varies widely among populations. Knowledge of the presence of third molar is important for treatment planning in orthodontics, pedodontics and forensic dentistry. Third molar has the highest incidence of tooth agenesis $(20 \%)^{2}$ and cases with such anomaly were found to have a 13 times higher chance of agenesis of remaining teeth. ${ }^{3}$ This illustrates how the status of third molar would affect the clinical presentation and the treatment planning process of different dental disciplines. The orthodontic literature demonstrates an interaction between third molars and occlusion. Individuals with agenesis of third molar have been shown to have a smaller mesiodistal width of remaining dentition, thus providing more space in the arch. ${ }^{4}$ Furthermore, agenesis of third molar germs was reported to depend on the anteroposterior dimensions of the maxilla (not the mandible) in orthodontic patients. ${ }^{5}$

\section{MATERIALS AND METHOD:}

A retrospective study of a total of 294 patients, of both genders ranging from 12 to 34 years of age who were orthodontically treated between August 2010 to May 2012 were reviewed from the files of the Department of Orthodontics, Dhulikhel Hospital, and Kathmandu University Hospital. The records included panoramic radiographs and study models of all patients with intra oral photographs at the beginning of the treatment. All the patients with permanent dentition stage, with complete adequate dental records were included in the study. The dental casts and photographs of the patients were assessed by a single technical operator. Sample comprised of males and females. Female were more, as is commonly anticipated in orthodontic practice, probably because of their great esthetic concern.

\section{RESULTS:}

A total of 294 orthodontic patients (94 male and 200 female) of 12 to 34 years of age group were evaluated for study with their orthopantomographs, study models, intra oral photographs and case history. The overview of the incidence of 1-4 third molars agenesis in both sexes at the age between $12-34$ years inclusive is shown in Table 1. 
In the study out of 294 subjects $32 \%$ were male and $68 \%$ were female. The results from two observers were analyzed for both maxillary and mandibular third molars showing insignificant inter-observer bias. Agenesis of the third molars was found to be $12.58 \%$ (Fig. 1). Prevalence of missing third molars $18,28,38$ and 48 were found to be $15.64 \%, 14.28 \%, 8.84 \%, 11.56 \%$ respectively. Agenesis was found to be more in males $(67.02 \%)$ than in females (42.5\%) (Fig. 2).

All the four third molars were absent in $8(2.72 \%)$ out of 294 subjects. Agenesis of third molars in maxilla was found in 30 subjects (10.2\%) and in mandible in 24 subjects (8.16\%) (Fig. 3).

Table 1- Distribution of agenesis of third molars in various age groups.

\begin{tabular}{|c|c|c|c|c|c|c|c|c|c|c|}
\hline \multirow{2}{*}{$\begin{array}{l}\text { Age } \\
\text { group }\end{array}$} & \multicolumn{2}{|c|}{ total no of patients } & \multicolumn{2}{|c|}{ agenesis of 18} & \multicolumn{2}{|c|}{ agenesis of 28} & \multicolumn{2}{|c|}{ agenesis of 38} & \multicolumn{2}{|c|}{ agenesis of 48} \\
\hline & male & female & male & female & male & Female & male & female & male & female \\
\hline 12 & 5 & 13 & & & 2 & & 2 & 2 & 2 & 2 \\
\hline 13 & 6 & 8 & 2 & 6 & 1 & 3 & 2 & & 2 & \\
\hline 14 & 6 & 6 & & & & & 2 & & 2 & \\
\hline 15 & 7 & 13 & 4 & 2 & 4 & & 2 & & 2 & \\
\hline 16 & 19 & 19 & 3 & 3 & 3 & 1 & 2 & & 2 & \\
\hline 17 & 1 & 1 & & & & & & & & \\
\hline 18 & 8 & 20 & & 2 & & & & 2 & & 2 \\
\hline 19 & 4 & 28 & & 2 & & 4 & & & & 3 \\
\hline 20 & 11 & 11 & 4 & 2 & 3 & 3 & & 2 & & 3 \\
\hline 21 & 2 & 18 & 2 & 2 & 2 & 4 & & 2 & & 2 \\
\hline 22 & 8 & 16 & & 2 & & 4 & & & & \\
\hline 23 & 7 & 23 & 1 & 3 & & 2 & & & & 4 \\
\hline 24 & & 2 & & & & & & & & \\
\hline 25 & 3 & 5 & & & & & 2 & & 2 & \\
\hline 26 & & 6 & & & & & & 2 & & \\
\hline 27 & 3 & 5 & & 2 & & 2 & & & & \\
\hline 28 & & 3 & & & & & & & & 2 \\
\hline 29 & & & & & & & & & & \\
\hline 30 & & 3 & & 2 & & 2 & & 2 & & 2 \\
\hline 31 & & & & & & & & & & \\
\hline 32 & 1 & & & & & & & & & \\
\hline 33 & & & & & & & & & & \\
\hline 34 & 3 & & 2 & & 2 & & 2 & & 2 & \\
\hline TOTAL & 94 & 200 & 18 & 28 & 17 & 25 & 14 & 12 & 14 & 20 \\
\hline
\end{tabular}

Fig. 1 : overall agenesis of third molar teeth.

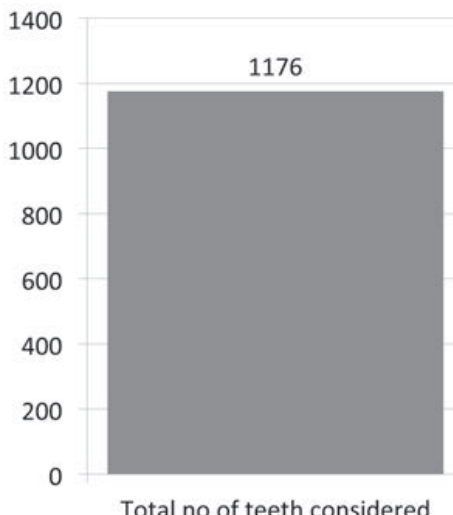

Total no of teeth considered
$148(12.58 \%)$

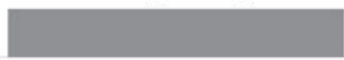

Agenesis of third molar 
Fig. 2 : Frequency of agenesis of individual third molar tooth

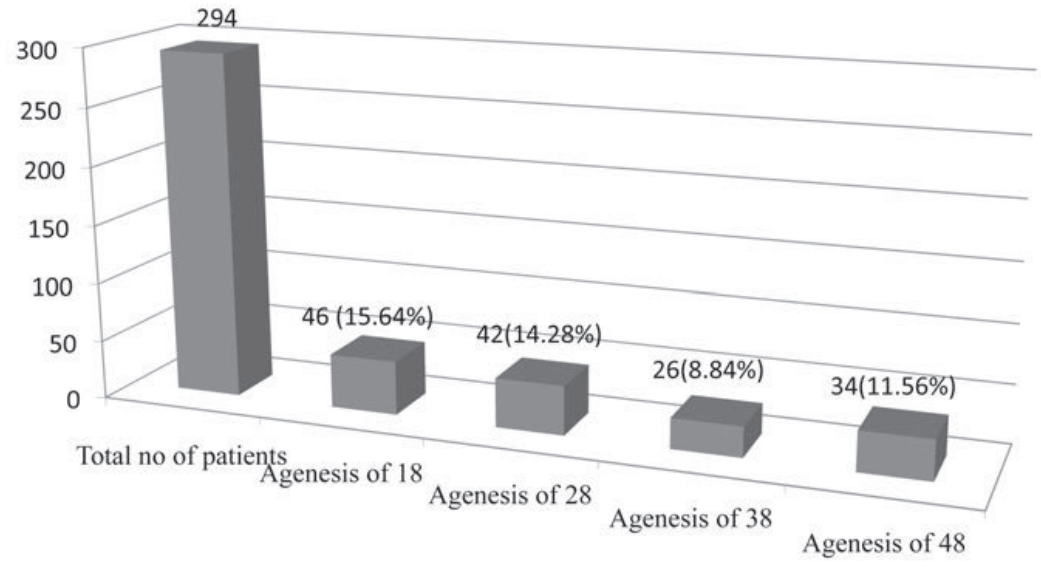

Fig. 3 : Frequency of agenesis of maxillary and mandibular teeth

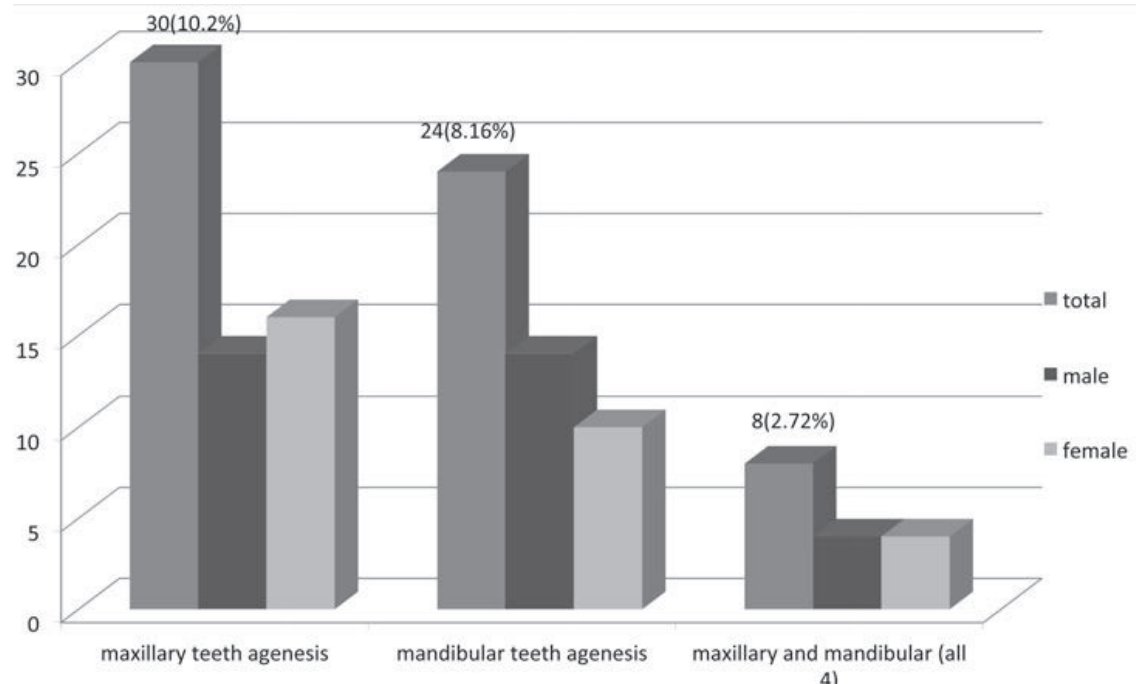

\section{DISCUSSION:}

The term agenesis of third molar means congenitally missing of one, two, three or four third molars. In every study it is necessary to consider not only the number of monitored individuals, but also the number of congenitally missing third molars. Variability of the third molar development gives every group a unique character. Differences between both sexes always exist. They are given not only by the different frequency of agenesis incidence, but also by its relevancy. Calcifications of crowns of the permanent teeth, except the third molars, start at the age three and are generally complete by the age six. ${ }^{6}$ In some individuals, there may be delayed development of premolars; hence, no one can be absolutely certain that these teeth are missing below the age of about nine years, especially among males. ${ }^{7}$
Wisth et al. ${ }^{8,9}$ proved that the prevalence of missing teeth is higher when examined at the age of seven years compared with nine years of age. At seven, 7.1 percent of the children had missing teeth, while two years later, only 6.6 percent of the same sample was diagnosed with hypodontia. For that reason, only patients older than 12 years old were included in the present study sample. In the present study, the prevalence of agenesis of third molar has been found to be $50.04 \%$ (male $67.02 \%$ and female $42.5 \%$ ), which is quite significant. Many studies have demonstrated that there was no consistent finding as to which jaw has more missing teeth. However, Chung et $\mathrm{l}^{10}$ found that hypodontia was significantly more in the mandible. Tooth agenesis, in the present study, was more commonly seen in the maxilla, which is consistent with 
the study of Fekonja. ${ }^{11}$ When comparing incidence of third molar agenesis in upper and lower jaws, our result displays more prevalence rate on upper jaw (88 on upper jaw and 60 on lower jaw). A similar result was shown by Garn et al. ${ }^{12}$ These results are sporadic, majority of authors refer about dominancy in the upper jaw when talking about the incidence of this anomaly and belong with their results are of Sonnabend, ${ }^{13}$ Krekeler et al., ${ }^{14}$ Hölzl, ${ }^{15}$ Grahnén. ${ }^{16}$ Approximately similar findings are also described by Bredyet al., ${ }^{17}$ Adler and Adler-Hradecky, ${ }^{18}$ Hübenthal ${ }^{18}$ and Speckin. ${ }^{19}$

\section{CONCLUSION:}

The prevalence of third molar tooth agenesis was found to be $50.34 \%$ percent for the orthodontic patient population of 12 to 34 years age group. Third molar tooth agenesis was more frequently found in males than in females and in the maxilla than in the mandible. The most frequently missing third molars were the maxillary third molars followed by the mandibular third molars. A detailed study which considers all aspects of the third molar agenesis is to be conducted on a larger sample of Nepalese population, to get reliable data on the third molar agenesis.

\section{REFERENCES}

1. Cameron J, Sampson W J. Hypodontia of the permanent dentition.Case reports. Australian Dental Journal, 1996; 41: 1-5.

2. Lavelle CL, Ashton EH, Flinn RM. Cusp pattern, tooth size andthird molar agenesis in the human mandibular dentition. ArchOral Biol. 1970; 15:227-37.

3. Bailit HL. Dental variation among populations.An anthropologicview. Dent Clin North Am. 1975; 19:125-39.

4. Keene HJ. A possible source of error related to the comparisonof odontometric data in different age groups. J Dent Res. 1964; 43:1255.

5. Kajii TS, Sato Y, Kajii S, Sugawara Y, lida J. Agenesis of third molar germs depends on sagittal maxillary jaw dimensions in orthodontic patients in Japan. Angle Orthod. 2004; 74:337-42.

6. Zhu JF, Marcushamer M, King DL, Henry RJ. Supernumerary and congenitally absent teeth: A literature review. J Clin Pediatr Dent. 1996; 20:87-95.

7. Ng'ang'a RN, Ng'ang'a PM. Hypodontia of permanent teeth in a Kenyan population. East Afr Med J. 2001; 78:200-3.

8. Wisth PJ, Thunold K, Böe OE. Frequency of hypodontia in relation to tooth size and dental arch width. Acta Odontol Scand. 1974; 32:201-6.

9. Rosenzweig KA, Garbarski D. Numerical aberrations in the permanent teeth of grade school children in Jerusalem. Am J Phys Anthropol. 1965;23:277-83.

10. Chung CJ, Han JH, Kim KH. The pattern and prevalence of hypodontia in Koreans. Oral Dis. 2008; 14:620-5.

11. Fekonja A. Hypodontia in orthodontically treated children. Eur J. Orthod. 2005; 27:457-60.

12. Garn S. M., Lewis A. B., Vicinus J. H: Third molar agenesis and reduction in the number of other teeth. J. Dent. Res. 1962, 41, 717-729.

13. Sonnabend F: ZurUnterzahl der Zähneinsbesondere der drittenMolaren. Dtsch. Zahn-Mund-Kieferheilk. 1966, 46, 1-3, p. 34-43.

14. Krekeler B, Scharf F, Tröndled. Röntgenstatistische Untersuchungenüber Nichtanlage und Dystopien der Weisheitszähne. Dtsch. zahnärztl. Z. 1974, 29, 591-593.

15. Hölzl F. ZurHypodontie des Weisheitszahnes. Med. Diss., Bonn 1972.

16. Bredy E, Erbring $\mathrm{CH}$, Hübenthal B: Häufigkeit der Zahnunterzahlbei Anlage und Nichtanlage vonWeisheitszähnen. Dtsch. ZahnMund-Kieferheilk. 1991, 79, 357-363.

17. Adler R, Adler-hradecky C: Die Agenesie des Weisheitszahnes. Dtsch. zahnärztl. Z. 1963, 23, 1361-1369.

18. Hubenthal B: BeitragzumZusammenhangzwischen den Anomalien der Zahnzahl und der Weisheitszahnanlage. Med. Diss., Halle-Wittenberg 1989.

19. Speckin j: Bestehtein Zusammenhangzwischenallgemeiner Hypodontie und der Nichtanlage der drittenMolaren? Med. Diss., Hamburg 1981. 